\title{
IMPEMENTASI MEDIA PEMBELAJARAN PENDIDKAN AGAMA ISLAM UNTUK MENINGKATKAN BELAJAR SISWA DI SEKOLAH DASAR
}

\author{
Nanang Durahman ${ }^{1}$, Deni Ahmad Jakaria² \\ Prodi Manajemen Informatika, STMIK DCI, Email : nanang@stmik-dci.ac.id ${ }^{1}$ \\ Prodi Teknik Informatika, STMIK DCI, Email : deni@stmik-dci.ac.id ${ }^{2}$
}

\begin{abstract}
ABSTRAK
Perkembangan Tekologi yang semakin canggih sudah selayaknya dimanfaatkan dalam berbagai bidang, salah satunya pada dunia pendidikan kini sudah saatnya adanya transformasi pembelajaran dengan menggunakan tekologi tersebut agar terciptanya pendidikan yang lebih efektif dan efisien. dan ini menjadi tuntutan bagi para pengajar dalam mengembangkan kemampunan penggunaan teknologi tersebut yang harus digunakan saat pembelajaran. Penerapan Media pembelajaran sangat penting dalam pembelajaran sebagai alat bantu dalam menyampaikan materi belajar agar lebih mudah diterima.

Tujuan dari penelitian ini adalah Menciptakan media pembelajaran yang dapat meningkatkan kualitas hasil pembelajaran siswa, dengan media pembelajaran dapat membantu siswa menyerap matari belajar lebih baik, Metode Pengembangan media pembelajaran yang digunakan adalah model ADDIE (Analisis, Desain, Development, Implementasi, Evaluasi) yang dikembangkan oleh Dick and Carry pada tahun 1996 dan Sedangkan Metode Tahap pembuatan perangkat lunak dalam membuat Game Evaluasi menggunakan secara waterfall yang dikembangkan oleh Herbert D. Benington pada tahun 1956 yang terdiri dari analisa sistem, rancangan, pengkodean program, pengujian sistem, dan pemeliharaan.
\end{abstract}

Kata Kunci : Media Pembelajaran, Teknologi, Pendidikan, Belajar, Agama Islam.

\section{PENDAHULUAN}

Perkembangan teknologi saat ini semakin cepat sehingga mendorong perilaku manusia untuk cenderung meninggalkan cara-cara yagn sifatnya manual atau konvensional beralih ke cara yang modern. Oleh karena itu dalam segala bidang hendaknya dapat memanfaatkan kehadiran teknologi ini untuk dapat membantu dalam aktifiatas kehidupan sehari hari.

Salah satu bidang yang perlu menerapkan tekonlogi adalah Pembelajaran di Sekolah, Sistem belajar konvensional di sekolah diyakini sebagai sistem yang sudah tidak efektif lagi. berbagai konsep yang menyangkut kemampuan otak, kecerdasan, dan 
Nanang Durahman, Deni Ahmad Jakaria/ Jurnal Teknik Informatika Vol 8. No. 1 (2020) 11 - 20

kreativitas, berkembang semakin jauh dan semakin menguatkan argumentasi yang ingin mengoreksi kelemahan sistem belajar yang selama ini berlaku secara konvensional. Sistem pembelajaran yang konvensional memberikan kontribusi besar dalam menghasilkan aspek kelemahan. Oleh karena itu, telah tiba saatnya dilakukan berbagai inovasi pendidikan, bahkan reformasi pendidikan di sekolah atau bahkan reformasi pendidikan.

Dari berbagai teori yang berkembang dan praktek yang dilakukan di berbagai Negara, dalam melaksanakan gerakan pembaruan pendidikan pada dasarnya dapat ditarik kesimpulan adanya dua aspek pembaruan pendidikan yang penting, yaitu:

1. Pembaruan dalam pendekatan pembelajaran, yang menyangkut esensi, materi, dan metode pembelajaran yang terjadi karena pengaruh berbagai temuan teori/prinsip/konsep baru yang berkembang mengenai otak dan kecerdasan, serta dipicu oleh dimanika perubahan multidimensional dari lingkungan hidup dan kehidupan yang menuntut komitmen dan kemampuan yang makin tinggi dari sumber daya manusia;

2. Pemanfaatan

teknologi informasi/komunikasi yang sudah berkembang demikian canggih untuk menunjang tercapainya pembaruan strategi dan teknik pembelajaran. Berbagai pemikiran pembaharuan pembelajaran, yang juga disertai dengan praktek-praktek eksperimen atau pelaksanaannya di beberapa Negara, pada intinya bermuara pada sebuah semangat bersama dan common sense untuk melakukan reformasi pembelajaran. Hasil reformasi pada akhirnya harus dapat dinilai pada apa yang telah dicapai anak didik dalam kerangka meningkatnya kemampuan belajar untuk menguasai keahlian yang lebih tinggi, meningkatnya motivasi dan konsep diri.

Dari berbagai pemikiran pembaruan pendidikan, beberapa segi yang menonjol dalam reformasi pembelajaran berkaitan dengan perbedaan dalam perbandingan antara pendekatan konvensional dan pendekatan reformasi pembelajaran adalah bahwa dalam pendekatan konvensional proses pembelajaran berada di bawah pengendalian ketat oleh pengajar bersifat searah, guru sebagai sumber pengetahuan tunggal, dan evaluasinya diorientasikan pada penguasaan materi. Sedangkan pada pembelajaran pendekatan reformasi pembelajaran siswa aktif melakukan eksplorasi, menggunakan model pembelajaran interaktif, guru bertindak sebagai fasilitator serta evaluasi dilaksanakan berbasis kinerja atau kecakapan hidup.

Barbara Means, dkk (dalam Ace Suryadi, 2008) menyatakan bahwa katalis untuk transformasi pembelajaran ialah pemusatan berbagai aspek di sekitar tugastugas yang disebut dengan istilah tugas otentik (authentic tasks). Tugas-tugas otentik menggantikan pendekatan pembelajaran yang berorientasi pada penguasaan subjek individual atau suatu kecakapan diskrit, yang tidak memiliki hubungan jelas dengan dunia nyata di mana peserta didik beraktivitas di luar sekolah.

Dalam gambaran konseptual tentang pemusatan berbagai aspek pembelajaran di sekitar tugas-tugas otentik, Ace Suryadi (2008) menunjukkan bahwa kegiatan pembelajaran harus berpusat pada subjek didik (all students practice, dan student eksploration) sehingga peran guru adalah sebagai fasilitator (teacher as facilitator) dan menggunakan berbagai bentuk strategi/model pembelajaran yang interaktif (interactive modes of instruction). 
Untuk mengimplementasikan tugastugas otentik tersebut model pembelajaran konstruktivis merupakan model pembelajaran paling optimal. Proses pembelajaran yang demikian juga merupakan proses pembelajaran bermakna. Dalam model pembelajaran konstruktivis agar proses pembelajaran bermakna terjadi secara optimal perlu tersedia berbagai sumber belajar berbasis aneka sumber dan teknologi. Salah satu sumber belajar berbasis teknologi komputer adalah multimedia pembelajaran interaktif.

Multimedia sebenarnya adalah suatu istilah generik bagi suatu media yang menggabungkan berbagai macam media baik untuk tujuan pembelajaran maupun bukan. Keragaman media ini meliputi teks, audio, animasi, video, bahkan simulasi. Tay (2000) memberikan definisi multimedia sebagai: kombinasi teks, grafik, suara, animasi dan video. Bila pengguna mendapatkan keleluasaan dalam mengontrol maka hal ini disebut multimedia interaktif. Bila multimedia interaktif dikembangkan dengan benar maka akan terwujud program pembelajaran yang sangat memudahkan proses belajar terutama bagi para peserta didik, baik penerimaan bahan ajar, simulasi dan evaluasi pembelajaran yang Interaktif, Dengan dikembangkan multimedia interaktif dimaksud diharapkan dapat membantu meningkatkan pembelajaran peserta didik di sekolah

\section{LANDASAN TEORI}

\subsection{Pengertian Media Pembelajaran}

Media pembelajaran adalah alat, metode, dan teknik yang digunakan sebagaí perantara komunikasi antara seorang guru dengan murid dalam rangka lebih mengefektifkan komunikasi dan interaksi antara guru dan siswa dalam proses pembelajaran di sekolah.

\section{$\begin{array}{ll}2.2 & \text { Pengertian } \\ & \text { Pembelajaran }\end{array}$}

Multimedia

Vaughan (2006) mengatakan bahwa multimedia adalah kombinasi teks, seni, suara, animasi, dan video yang disampaikan kepada orang dengan komputer atau petalatau manipulasi elektronik dan digital lainnya.

\subsection{Pengertian Desain Pembelajaran}

Istilah pengembangan sistem pembelajaran (instructional system development ) dan desain pembelajaran (intructíonal design) sering dianggap sama, atau setidaknya tidak dibedakan secarategas dalarn penggunaannya meskipun menurut arti katanya ada perbedaan antara "desain" dan "pengembangan". Kata "desain" berarti membuat sketsa atau pola atau ouzlíne atau rencana pendahuluan, sedangkan "pengernbangan" berarti membuat tumbuh secara teratur untuk menjadikan sesuatu lebih besar, lebih baik, lebih efektif, dan sebagainya.

\subsection{Pengertian Adobe Flash}

Menurut Darmawan (2014: 259) Adobe Flash merupakan perangkat lunak komputer yang digunakan untuk membuat animasi, video, gambar, vektor, bitmap, dan multimedia interaktif. Animasi yang dihasilkan oleh Flash mempunyai extensi *.swf, yang dapat dijalan dengan menggunakan Adobe Flash Player.

\section{ANALISIS MASALAH}

Pendidikan memegang peranan penting dalam proses peningkatan kualitas sumber daya manusia karena pendidikan merupakan sarana untuk melahirkan generasi muda yang berkualitas. Pada dasarnya pendidikan merupakan suatu upaya yang dapat memberikan pengetahuan, wawasan, keterampilan, dan keahlian tertentu kepada peserta didik guna mengembangkan bakat dan 
Nanang Durahman, Deni Ahmad Jakaria/ Jurnal Teknik Informatika Vol 8. No. 1 (2020) 11 - 20

kepribadian mereka. Untuk dapat meningkatkan kualitas sumber daya tersebut perlu adanya peningkatan dalam dunia pendidikan. Salah satu yang harus dilakukan dalam meningkatkan kualitas pendidikan adalah pengembangan media pembelajaran. Dalam dunia pendidikan media dikenal sebagai alat bantu dalam proses pembelajaran untuk mencapai tujuan pembelajaran .

Tercapainya tujuan pendidikan apabila proses pembelajaran dapat berjalan dengan baik dan Informasi yang terdapat dalam media juga harus dapat melibatkan peserta didik dalam bentuk aktivitas yang nyata, sehingga pembelajaran dapat terjadi dengan efektif. Media yang digunakan dalam proses pembelajaran cukup beragam, mulai dari media yang sederhana sampai yang canggih. Maka dari itu, guru dituntut untuk selalu berkembang dan meningkatkan kemampuan dalam penggunaan media pembelajaran guna mempermudah dalam menyampaikan pembelajaran serta mempermudah peserta didik dalam memahami materi yang disampaikan dalam pembelajaran itu sendiri.

Berdasarkan hasil wawancara
diperoleh bahwa seiring dengan penggunaan power point yang terlalu sering dengan umumnya berupa teks dan gambar tanpa melibatkan peserta didik dalam penggunaan media maka menjadikan peserta didik kurang antusias dalam mengikuti pelajaran. Materi yang disampaikan lebih sulit untuk diterima dalam memori peserta didik karena media pembelajaran yang digunakan kurang menarik dan membosankan bagi peserta didik. Hal ini berbeda apabila pembelajaran menggunakan media pembelajaran Interaktif karena media ini menggunakan komputer sebagai alat bantu dalam proses pembelajaran yang mampu membuat peserta didik lebih aktif selama pembelajaran berlangsung karena peserta didik dapat menjalankan sendiri media pembelajaran yang diberikan .

Penggunaan media dalam pembelajaran juga harus menyesuaikan karakter media dengan kebutuhan peserta didik agar dapat menumbuhkan motivasi dan minat belajar peserta didik sehingga peserta didik mudah memahami pelajaran. Media pembelajaran Computer berbasis Adobe Flash diharapkan dapat menunjang proses pembelajaran sehingga peserta didik tidak merasa bosan ketika proses pembelajaran berlangsung. Karena media ini dilengkapi dengan berbagai macam ilustrasi gambar yang nyata dan video animasi yang menarik.

\subsection{Spesifikasi Produk yang Diharapkan}

Penelitian pengembangan ini diharapkan mampu menghasilkan produk berupa media pembelajaran ekonomi berbasis Adobe Flash pada materi perpajakan dengan spesifikasi produk yaitu :

1. Produk yang dihasilkan adalah media pembelajaran dan Game Evaluasi dengan menggunakan software Adobe Flash CS4 dan Borland Delphi

2. Bagian-bagian yang terdapat didalam produk media pembelajaran adalah :

a. Halaman intro sebagai halaman pembuka dengan judul pokok bahasan materi .

b. Menu utama media yang terdiri dari menu-menu petunjuk penggunaan media, KD dan Indikator, tujuan pembelajaran, materi, video, latihan soal, evaluasi, profil peneliti dan daftar pustaka atau referensi .

c. Menu materi yang didalamnya terdapat isi dari materi tentang sejarah nabi

d. Menu Latihan soal, terdapat sepuluh soal pilihan ganda yang dapat langsung dilihat hasil skor yang diperoleh . 
3. Bagian-bagian yang terdapat didalam produk Game Evaluasi adalah :

a. Halaman Depan sebagai halaman Tampilan Game terdapat Pengaturan Nama Kelompok, Nilai dan Penggunaan

b. Halaman Input Soal untuk menambahkan soal dan mengubah soal

c. Halaman Pemilihan Soal pada saat menjalankan game

d. Halaman Panduan Langkah dalam menjalankan game

\subsection{Pentingnya Pengembangan}

Pengembangan media pembelajaran berbasis Adobe Flash dilakukan sebagai upaya untuk memperkaya Media pembelajaran di Sekolah Dasar. memiliki aspek-aspek yang dapat meningkatkan efektifitas pembelajaran yaitu aspek umpan balik, penilaian, monitoring kemajuan, petunjuk, dan tampilan. Media Pembelajaran dapat secara cepat berinteraksi dengan individu, dapat secara langsung digunakan untuk menyampaikan materi dan memberikan latihan tes kemampuan untuk peseta didik.

\subsection{Asumsi dan Keterbatasan}

1. Asumsi

Asumsi pengembangan media pembelajaran ini adalah :

a. Media pembelajaran berbasis Adobe Flash memiliki kemampuan menggabungkan audio visual dan bentuk teks, gambar, animasi, dan video sehingga dapat merangsang peserta didik dalam mengikuti pembelajaran .

b. Media dibuat merupakan media pembelajaran yang menarik dan menggunakan bahasa yang mudah dipahami peserta didik . c. Guru dan peserta didik mampu mengoperasikan komputer dengan baik sehingga memudahkan untuk menggunakan media yang dikembangkan .

\section{Keterbatasan Pengembangan}

a. Media pembelajaran menggunakan Adobe Flash ini terbatas pada satu pokok bahasan materi

b. Model penelitian yang digunakan terbatas pada model pengembangan ADDIE yang terdiri dari analysis, desain, development, implementation and evaluation.

c. Media tidak dapat dibuka di handphone ataupun tablet .

\section{PERANCANGAN SISTEM}

Perancangan sistem merupakan tahap selanjutnya setelah analisa sistem, mendapatkan gambaran dengan jelas tentang apa yang dikerjakan pada analisa sistem, maka dilanjutkan dengan memikirkan bagaimana membentuk sistem tersebut.

\subsection{Flowcart Media Pembelajaran}

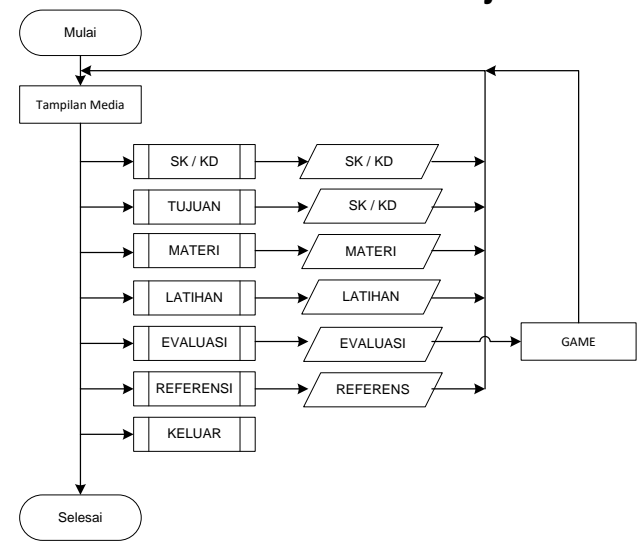

Gambar 4.1

Flowcart Media Pembelajaran 


\subsection{Rancangan Tampilan Depan}

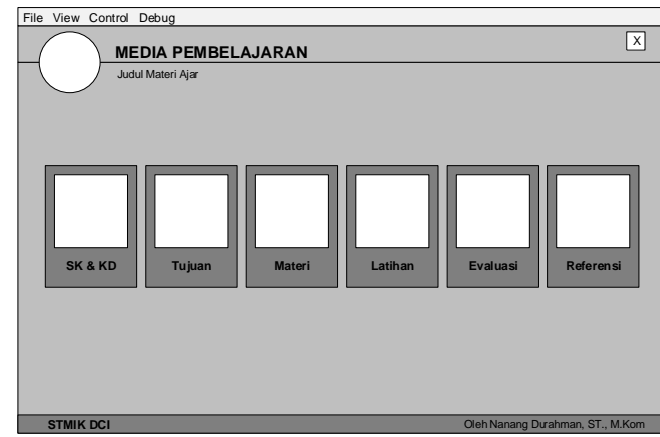

Gambar 4.2

Rancangan Tampilan Depan

\subsection{Rancangan Slide SK KD}

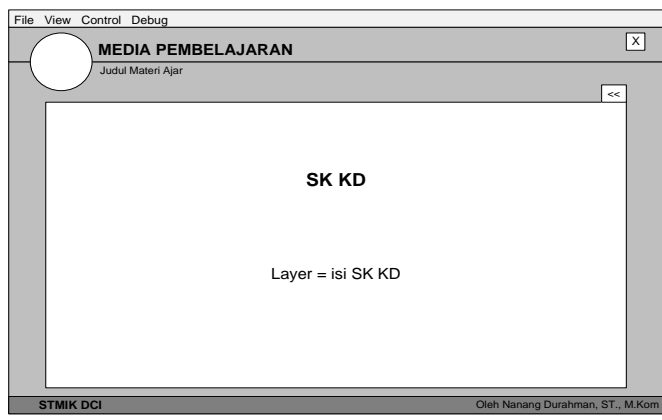

Gambar 4.3

Rancangan Slide SK KD

\subsection{Rancangan Slide Video Praktek}

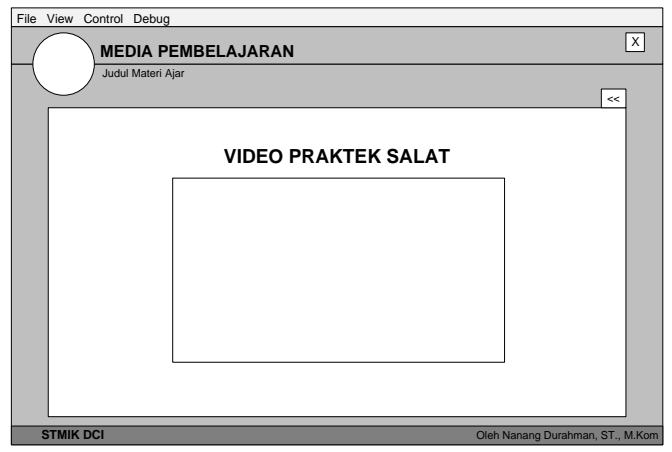

Gambar 4.4

Rancangan Slide Video Praktek
4.5 Rancangan Slide Galeri Foto

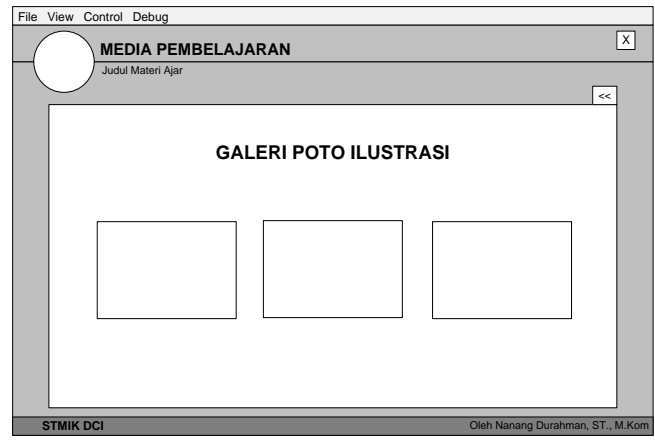

Gambar 4.5

Rancangan Slide Galeri Foto

\subsection{Rancangan Slide Materi Salat}

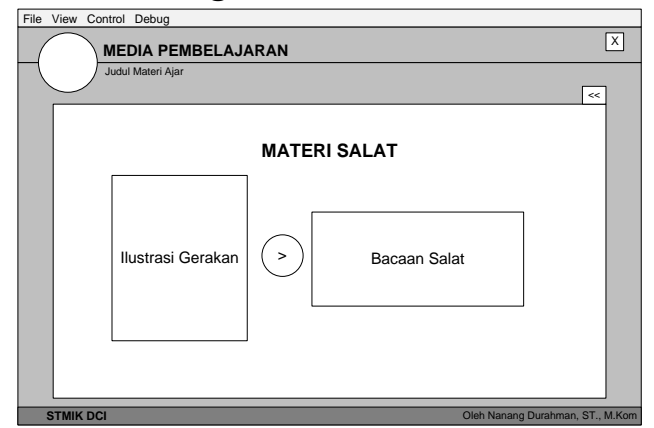

\section{Gambar 4.6}

Rancangan Slide Materi Salat

V. IMPLEMENTASI

Pada implementasi program penyusun mengajukan beberapa tahapan yang harus dipersiapkan agar program aplikasi ini dapat berfungsi secara maksimal dan sebagaimana mestinya.

Adapun tahapan yang harus dilakukan adalah:

Perangkat Keras (Hardware) dan Perangkat Lunak (Software) Yang Digunakan Dalam Pengimplementasian Dalam Implementasi program diantaranya:

a. Perangkat Keras (Hardware) yang digunakan:

1. Intel core i3 $2.40 \mathrm{Ghz}-2.4 \mathrm{Ghz}$

2. Memory $2 \mathrm{~GB}$

3. Hardisk 500GB

4. VGA RADEON GRAPHICS HD 7340

5. Monitor Generic PnP 
Nanang Durahman, Deni Ahmad Jakaria/ Jurnal Teknik Informatika Vol 8. No. 1 (2020) 11 - 20

b. Perangkat Lunak (Software) yang digunakan:

1. Sistem Operasi

2. Adobe Cs Flash

3. Delphi

4. Microsoft Word 2010

5. Microsoft Visio 2010

\subsection{Screenshoot / Capture Program}

1. Tampilan Media

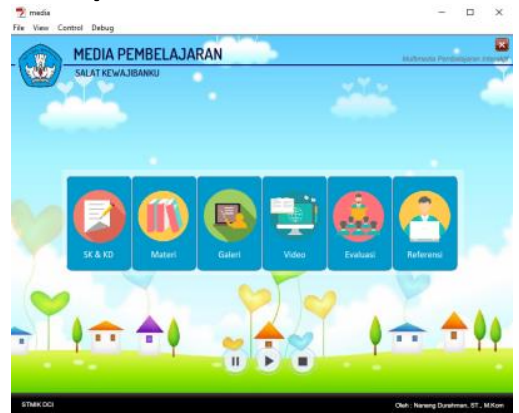

Gambar 5.1

Tampilan Media

2. Tampilan Depan

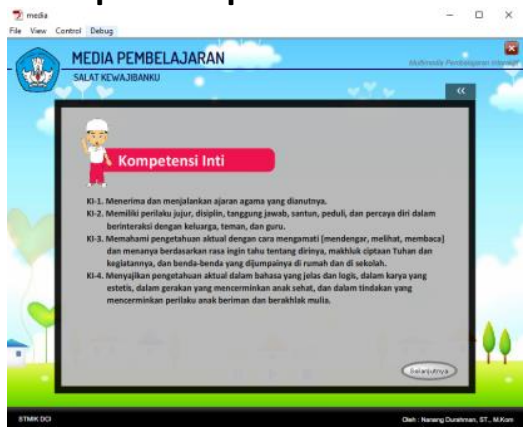

Gambar 5.2

Tampilan Depan

3. Tampilan Materi

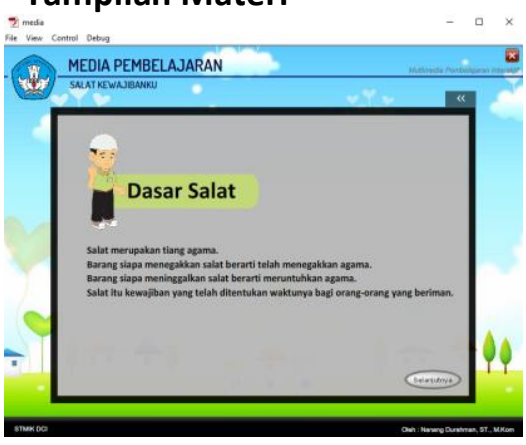

Gambar 5.3

Tampilan Materi

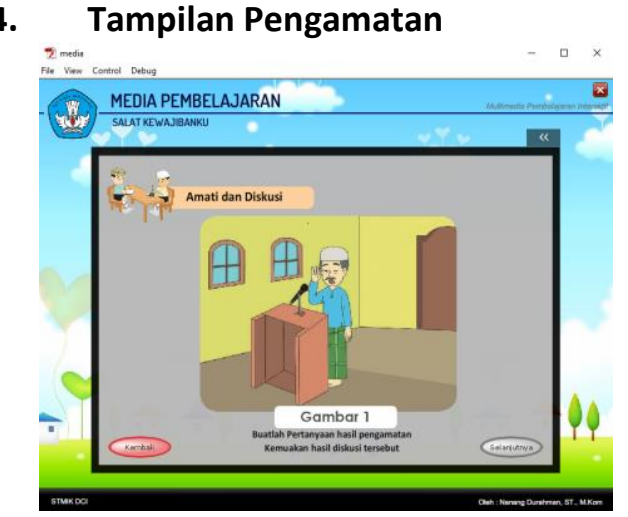

Gambar 5.4

Tampilan Pengamatan

5. Tampilan Ilustrasi dan Bacaan

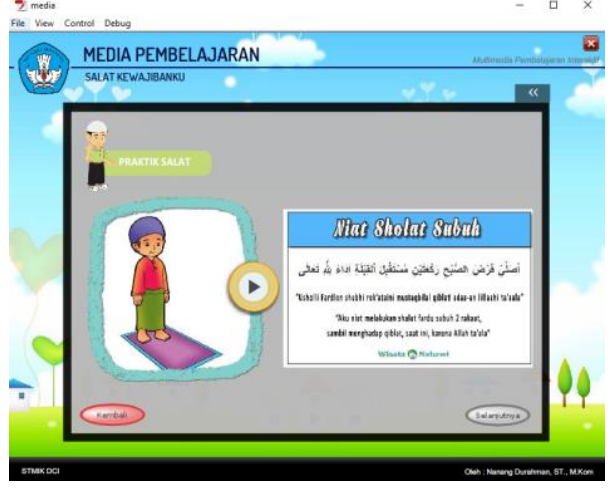

Gambar 5.5

Tampilan Ilustrasi dan Bacaan

6. Tampilan Pengamatan

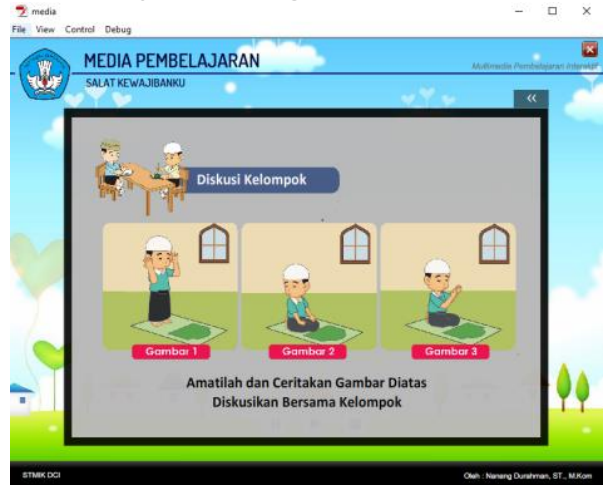

Gambar 5.6

Tampilan Pengamatan 
Nanang Durahman, Deni Ahmad Jakaria/ Jurnal Teknik Informatika Vol 8. No. 1 (2020) 11 - 20

7. Tampilan Materi Simulasi Shalat pada Video

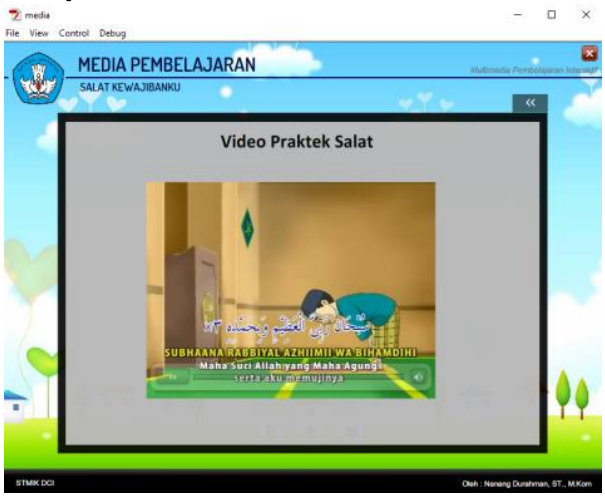

Gambar 5.7
8. Tampilan Referensi

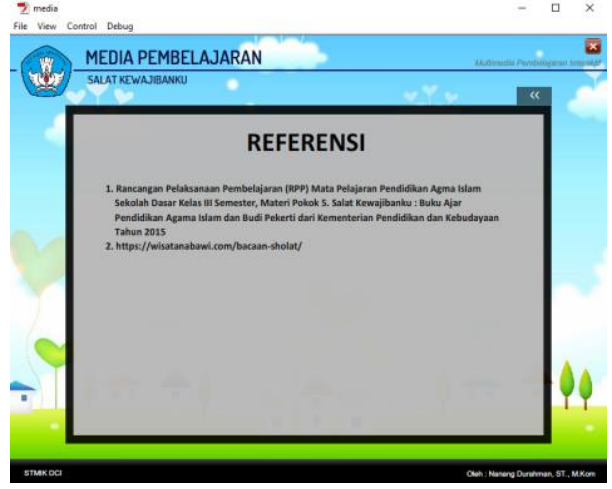

Gambar 5.8

Tampilan Referensi

Tampilan Materi Simulasi Salat pada

Video

\subsection{Pengujian Media}

Tabel 5.1

Tabel Pengujian Media

\begin{tabular}{|c|c|c|c|}
\hline Deskripsi Uji & $\begin{array}{l}\text { Langkah-langkah } \\
\text { Melakukan Uji Fungsi }\end{array}$ & $\begin{array}{l}\text { Hasil yang } \\
\text { Dapatkan }\end{array}$ & $\begin{array}{c}\text { Hasil } \\
\text { PengujianD } \\
\text { iterima/Tid } \\
\text { ak } \\
\end{array}$ \\
\hline $\begin{array}{l}\text { Tampilkan } \\
\text { halaman } \\
\text { Kompetensi Inti } \\
\text { dan Dasar }\end{array}$ & $\begin{array}{l}\text { 1. Klik Menu KI dan KD } \\
\text { 2. Buka Halaman KI } \\
\text { 3. Buka Halaman KD }\end{array}$ & $\begin{array}{l}\text { Dapat } \\
\text { menampilkan } \\
\text { daftar Kompetensi } \\
\text { Inti dan Dasar }\end{array}$ & Diterima \\
\hline $\begin{array}{l}\text { Tampilkan } \\
\text { halaman } \\
\text { Kompetensi Inti } \\
\text { dan Dasar }\end{array}$ & $\begin{array}{l}\text { 1. Klik Menu Materi } \\
\text { 2. Klik Tombol } \\
\text { Selanjutnya untuk } \\
\text { menampilkan } \\
\text { kelanjutan materi } \\
\text { 3. Klik Tombol Play } \\
\text { Audio Materi }\end{array}$ & $\begin{array}{l}\text { Dapat } \\
\text { menampilkan } \\
\text { materi } \\
\text { pembelajaran }\end{array}$ & Diterima \\
\hline $\begin{array}{l}\text { Tampilkan } \\
\text { halaman Materi } \\
\text { Ajar dari Video }\end{array}$ & Klik Menu Video & $\begin{array}{l}\text { Dapat } \\
\text { menampilkan } \\
\text { halaman Video }\end{array}$ & Diterima \\
\hline
\end{tabular}




\begin{tabular}{|l|l|l|l|}
\hline $\begin{array}{l}\text { Tampilkan } \\
\text { halaman } \\
\text { Referensi }\end{array}$ & Klik Menu Rerefensi & $\begin{array}{l}\text { Dapat } \\
\text { menampilkan } \\
\text { halaman Referensi }\end{array}$ & Diterima \\
\hline
\end{tabular}

\section{KESIMPULAN}

Hasil Penelitian yang dihasilkan menciptakan dampak positif dari penggunaan media sebagai bagian pembelajaran yang efektif dan efisien. Setiap siswa yang melihat atau menderngar penyajian melalui media sehingga informasi yang sama dapat disampaikan kepada siswa sebagai landasan untuk pengkajian, latihan, dan aplikasi lebih lanjut. Dengan media tersebut dapat menunjukan daya tarik dan siswa untuk tetap memperhatikan pembelajaran dan menimbulkan motivasi untuk terus menyimak dan mengikuti pembelajaran, serta memperjelas penyajian materi pembelajaran sehingga dapat memperlancar dan meningkatkan proses belajar yang efektif dan efisien.

Disamping itu proses pembelajaran menjadi lebih jelas, menarik dan Interaktif berdasarkan materi yang disisipkan gambar video hal tersebut dapat menciptakan suasana belajar menjadi hidup tidak monoton dan tidak membosankan sehingga pembelajaran dengan media akan menciptakan komunikasi dua arah secara aktif, guru dan siswa akan terlibat langsung dalam pembelajaran tersebut. Pada akhirnya hasil dari Pembelajaran adalah bagaimana dapat meningkatkan Meningkatkan kualitas hasil pembelajaran siswa, dengan media pembelajaran dapat membantu siswa menyerap materi belajar lebih baik.

\section{DAFTAR PUSTAKA}

Association for Educational Comunication Technology (AECT), Definisi Teknologi

Pendidikan (Penerjemah Yusufhadi Miarso), Jakarta: C.V. Rajawali (Buku asli diterbitkan tahun 1977), 1986.

ercival, Fred \& Henry Ellington, A Handbook of Educational Technology, Kogan Page Ltd, 120 Pentonville Road, London., 1980.

Suryadi, Ace, 2008, Reformasi Sistem Pembelajaran, Bandung: Universitas Pendidikan Bandung

Sutisna, Herlan, Agung Baitul Hikma. Pemanfaatan Teknologi Adobe Flash dan MDLC untuk Animasi Pengenalan Pakaian Teradisional Indonesia. Jurnal JUMIKA Vol. 6 No.1 : LPPM STMIK DCI

Haviz, Muhammad. 2013. Research and Development Penelitian Dibidang Kependidikan Yang Inovatif, Produktif Dan Bermakna. Padang. Jurnal Pendidikan Biologi. Universitas Negeri Padang. (Vol. 16 No. $1 \mathrm{HIm}$. 28-42) 
Nanang Durahman, Deni Ahmad Jakaria/ Jurnal Teknik Informatika Vol 8. No. 1 (2020) 11 - 20

Arsyad, Azhar. 2014. Media Pembelajaran. Bilawa, Putra Muhamad, Nia Gresiana Putri. Jakarta: Rajawali Pers.

2018. Sistem Informasi Pengelahan Nilai Rapor Di Sekolah Menengah

Sanaky, Hujair AH. 2015. Media Kejuruan DCl Kota Tasikmalaya. Jurnal Manajemen Informatika Pembelajaran Interaktif Inovatif. (JUMIKA) Vol. 5 No.1 STMIK DCI

Yogyakarta: Kaukaba Dipantara.

Durahman, Nanang. Faizal Ali Saban. 2018. Rancang Bangun Alat Bantu Ajar Matematika untuk SD Adobe Flash CS 4. Jurnal Manajemen Informatika (JUMIKA) Vol. 5 No.1 : STMIK DCI 